脳動静脈奇形の病態と治療一Multimodal treatment 時代の直達術の現状と 将来展望一

栗田 浩樹，吉川 雄一郎，池田 俊貴，竹田 理々子，鈴木 海馬，鈴木 隼，上出 智也 埼玉医科大学国際医療センター脳卒中外科

\title{
Role of Direct Surgery for Arteriovenous Malformations in the Multi- modal Treatment Era
}

\author{
Hiroki Kurita, M.D., Ph.D., Yuichiro Kikkawa, M.D., Ph.D., Toshiki Ikeda, M.D., Ph.D., \\ Ririko Takeda, M.D., Ph.D., Kaima Suzuki, M.D., Ph.D., Shun Suzuki, M.D., and \\ Tomoya Kamide, M.D., Ph.D. \\ Department of Cerebrovascular Surgery, International Medical Center, Saitama Medical University
}

Recently, recommendations of managing cerebral arteriovenous malformations (AVMs) with multimodal treatment in conjunction with the completion of the ARUBA study have significantly reduced the number of direct surgeries for AVMs. Nevertheless, favorable safety profiles and cure rates can still be achieved with appropriate patient selection and judicious use of intraoperative support devices. In this article, we present our experience in the direct surgery of AVMs in the present setting, and discuss the central role of surgery to promote treatment outcomes. In addition, it is important to utilize practice-based data to establish indication criteria that reflects surgical outcomes.

(Received September 19, 2020 ; accepted October 7, 2020)

Key words : cerebral arteriovenous malformation, direct surgery, hybrid surgery, surgical assistance, treatment outcome

Jpn J Neurosurg（Tokyo）29: 845-851, 2020

\section{はじめに}

脳動静脈奇形 (cerebral arteriovenous malformation: AVM）に対する multimodal treatment が定着した現 在 ${ }^{47)} 722$ 23226)，直達術が果たす役割に関して種々の意見が あり, 施設間による治療戦略のバラツキも大きい.また, ARUBA study ${ }^{20)}$ の結果から, 最近では未出血例の治療適 応自体が疑問視されている。本稿では現時点における AVM に対する治療の標準化と個別最適化に関して直達 術が果たす役割について，具体的症例を提示しながら考
察する.

\section{当施設における AVM 治療の現状}

当施設は年間 50 例を超える AVM 患者を manage する high volume centerである。このうち 20 例程度は(1)無症 候性である, あるいは(2)治療に伴う risk が自然歴を上回 ることが予想される, などの理由により保存的加療が選 択されるが, 半数を超える症例 (年間 $20 \sim 30$ 例) では治 療介入が選択されている。積極的治療が考慮される場合 
Table 1 AHA recommendations for the management of intracranial AVMs (2001) (excerpt)

1. Surgery is strongly considered for SMG-I, II lesions

2. SRT is considered for SMG-I, II lesions with increasing surgical risk

3. Combined approach (TAE + surgery) is feasible for SMG-III lesions

4. Surgery only is not recommend for SMG-IV, V lesions

5. Multimodal treatment seems helpful for SMG-III, IV, V lesions

SMG : Spetzler-Martin grade, SRT : stereotactic radiation therapy, TAE : transarterial embolization

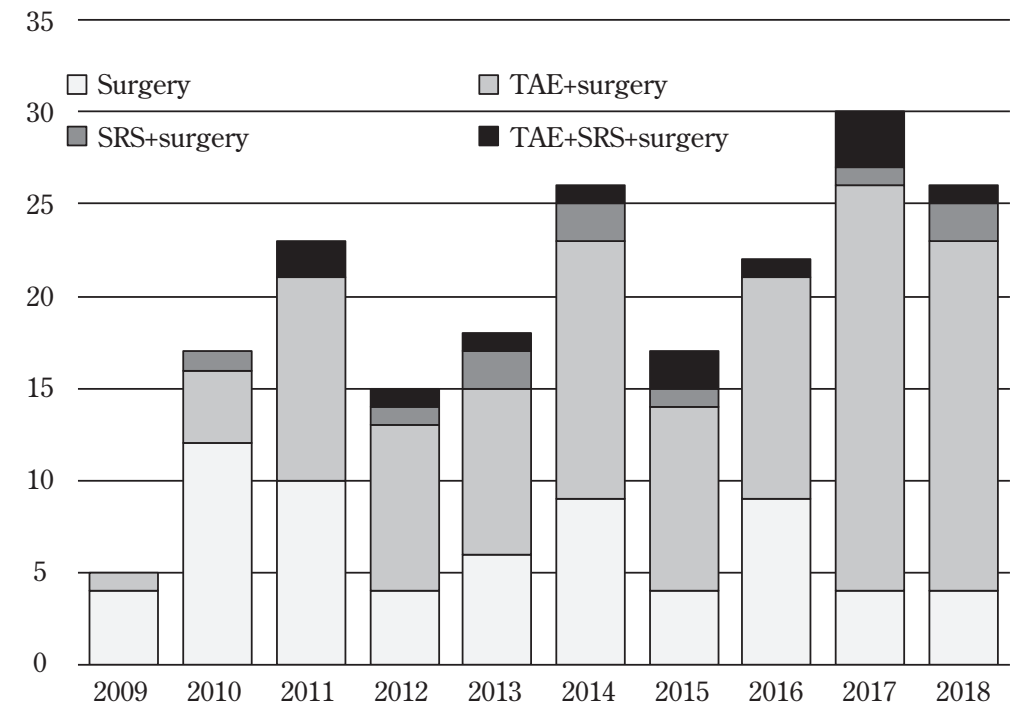

Fig. 1 Bar charts representing the number of direct surgery of AVMs in our institution during the past 10 years

A significant proportion of patients underwent endovascular transarterial embolization (TAE) and/or stereotactic radiosurgery (SRS) before the surgery.

は，すべての症例で，脳血管内治療科との合同カンファ レンスが開催され，統一した基準（structured approach） のもとに, 原則的に 2001年の American Heart Association (AHA) のガイドライン ${ }^{21)}$ (Table 1) に準拠した戦略を とっているが, low grade (Spetzler-Martin I, II ${ }^{27)}$ ) AVM の患者に対しても，安全に塞栓が可能と考えられるもの に関しては hybrid surgery として積極的に塞栓術を併用 している ${ }^{8)-12)}$ のが特徴である。当施設においては, ARUBA study 以降も直達術の件数は減少傾向にはなく, 現在でもAVMに対する main treatment modalityになって いるが，塞栓術や radiosurgery などの先行治療を受けた AVM に対する手術が経時的に増加している（Fig. 1).

\section{塞栓術後の AVM に対する直達術}

戦略的な transarterial embolization（TAE）による支援 は，以下の $2 つ の$ 点で現在の AVM 摘出術において最も 重要なコンセプトの 1 つである。第一は，nidusの裏か ら，あるいは eloquent area から入る feederの処理であ る。従来, AVM に対する手術は，血管構造を術中に直視 下に把握するために, nidus の長径に対して “perpendicular”に approach することが原則であったが, 塞栓術の併 用により，より “tangential” な approach が可能となり， 小型でも eloquent area にある病変や多系統の feederをも つ病変で有用である（Fig. 2)。第二は, high-flow で大型 の high-grade (Spetzler-Martin III〜V) AVM において も， staged TAEを併用することにより，術前に十分な段 階的 flow reduction が得られると，(1)摘出に伴う drastic 

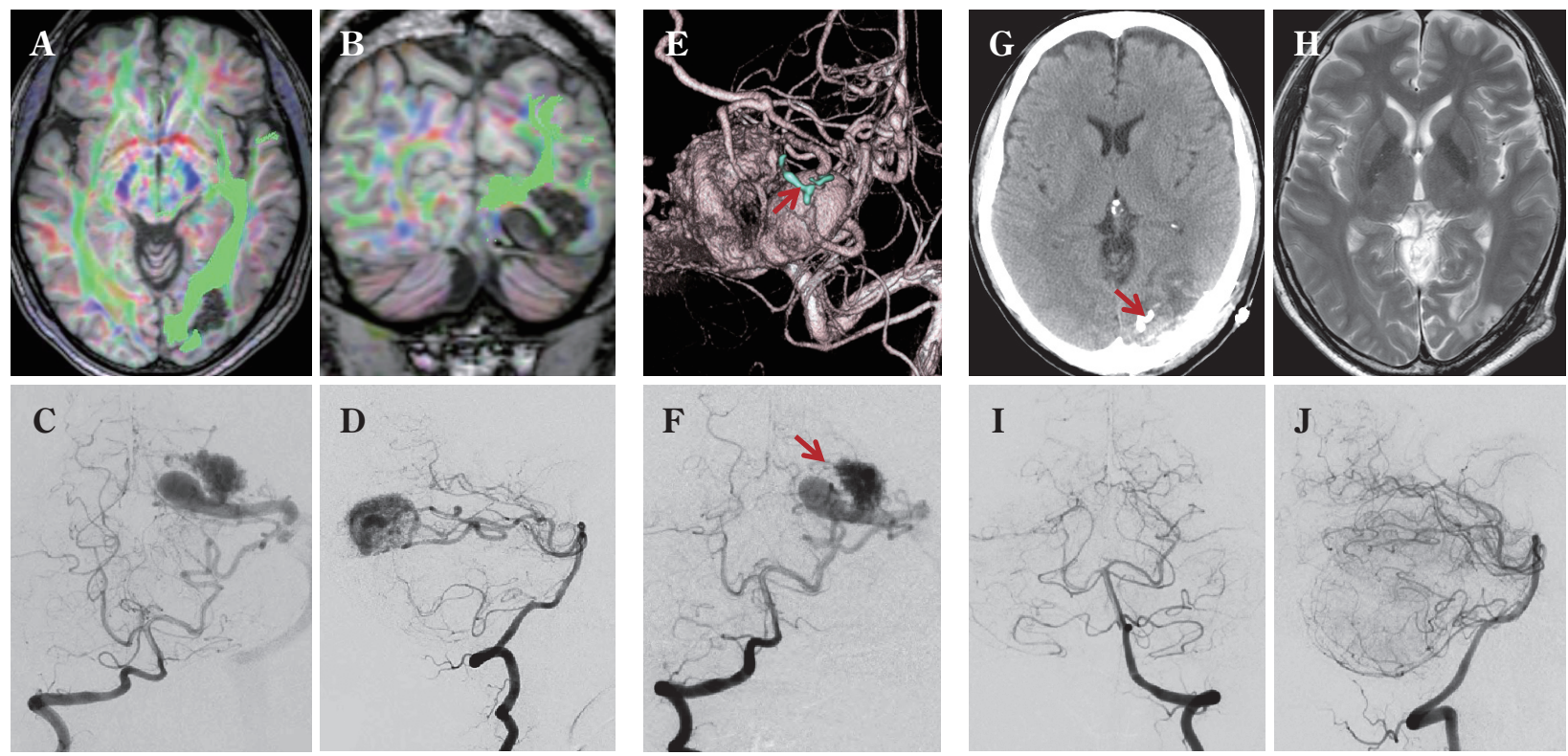

Fig. 2 Representative cases of hybrid surgery（application of TAE and resection in a single session) in patients with small AVMs presenting with symptomatic seizure [Reproduced from Ref. \#11, with permission]

A, B : Preoperative MRI-tractography showing a small AVM surrounded by optic radiation fibers in the left occipital lobe.

C, D : Preoperative angiograms showing a small nidus that is mainly fed by branches of posterior-temporal artery and drains into the transverse sinus.

E, F : Angiograms after targeted embolization of strategic medial feeder (E, arrow). Medial part of the nidus was occluded ( $\mathbf{F}$, arrow), and subsequently, the lesion was dissected from lateral side.

G : Postoperative CT showing the localization of the embolized feeder (arrow).

$\mathbf{H}$ : Postoperative MRI showing the preservation of visual cortex and optic radiation fibers. The patient showed no visual field defect.

I , J : Postoperative angiograms showing total removal of the AVM.

な周囲脳血流の変化が抑えられ, 術後の hemodynamic な 合併症が予防されること, (2) nidus の減圧により, nidus 自体を術中安全に牽引することが可能となり, 周囲の赤 虫血管の発達も少なく, nidus 表面ぎりぎりの plane で剥 離ができようになることである（Fig. 3)。手技の詳細や ポイントは他稿9)-15) に譲るが, 術前塞栓術の併用によ り, 摘出術の難度は確実に下がり, 近年の手術成績の飛 躍的向上に寄与している.

\section{Radiosurgery 後の AVM に対する直達術}

近年の radiosurgery の急速な普及により, 周囲に radiation-induced edema や radiation necrosis，あるいは cyst や cavernous malformation 様の repetitive な出血を生じて 進行性の神経学的悪化を生じる例が散見されるように なったが，当施設ではこのような変性 AVM に対する salvage treatment としての直達術の頻度も増加してい る。この病態の本質は, 周囲脳における radiation vascu- lopathy による血漿および血球成分の漏出であり, 手術で は, 変性した nidus とともに周囲の壊死巣を除去するこ とが重要である ${ }^{12)}$. 摘出後, 数力月で edemaは消退し, 神経症候も改善する. 変性した AVM 自体は血流が scanty のため, 手術の難度は一般的に低く, 最大 20 年の follow upで, 長期的にも cyst の再発や再出血を生じた症例は経 験していない (Fig.4).

\section{考 察}

新しい塞栓物質（Onyx）の認可や顕微鏡手術技術の進 歩, また必要に応じて術中 3D-angiography や superselective angiography, 塞栓術などが施行できるハイブ リッド手術室の普及により, AVM に対する直達術は, 近 年最も難度が低下した手術と思われる(1)-4)5)7)8)11)18)28)。 さらに従来 “normal perfusion pressure breakthrough (NPPB) syndrome”, あるいは “occlusive hyperemia” と 称された術後の hemodynamic complication も激減してお 

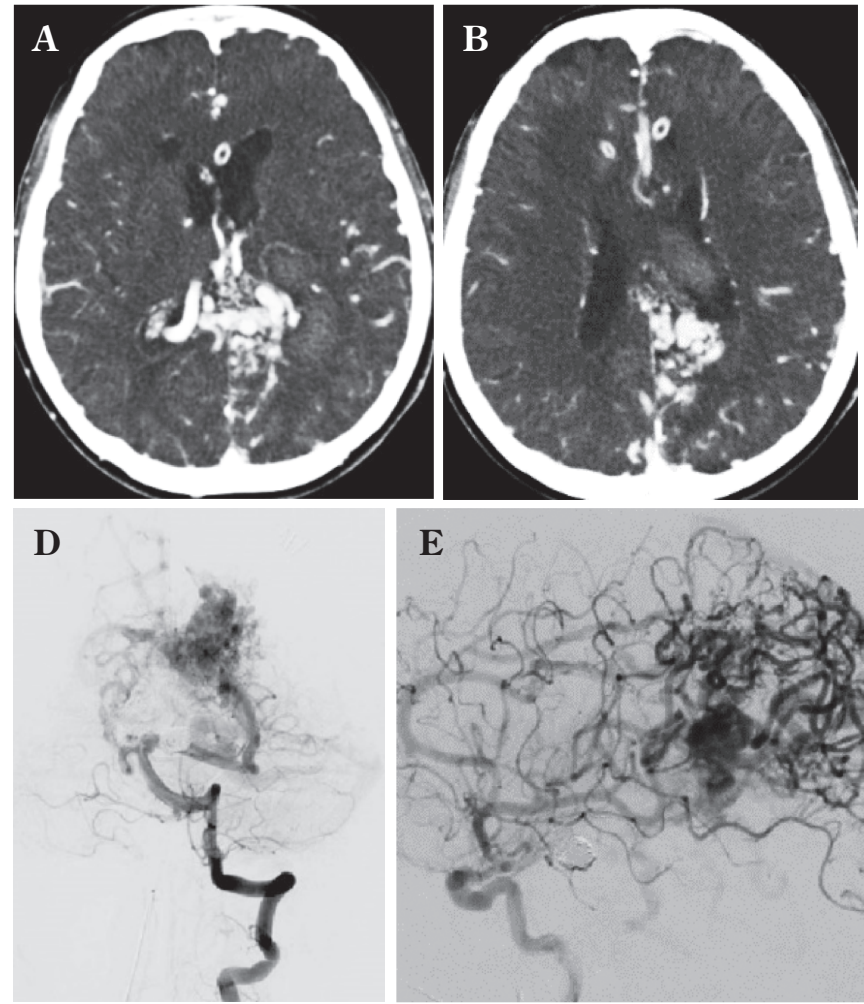

E
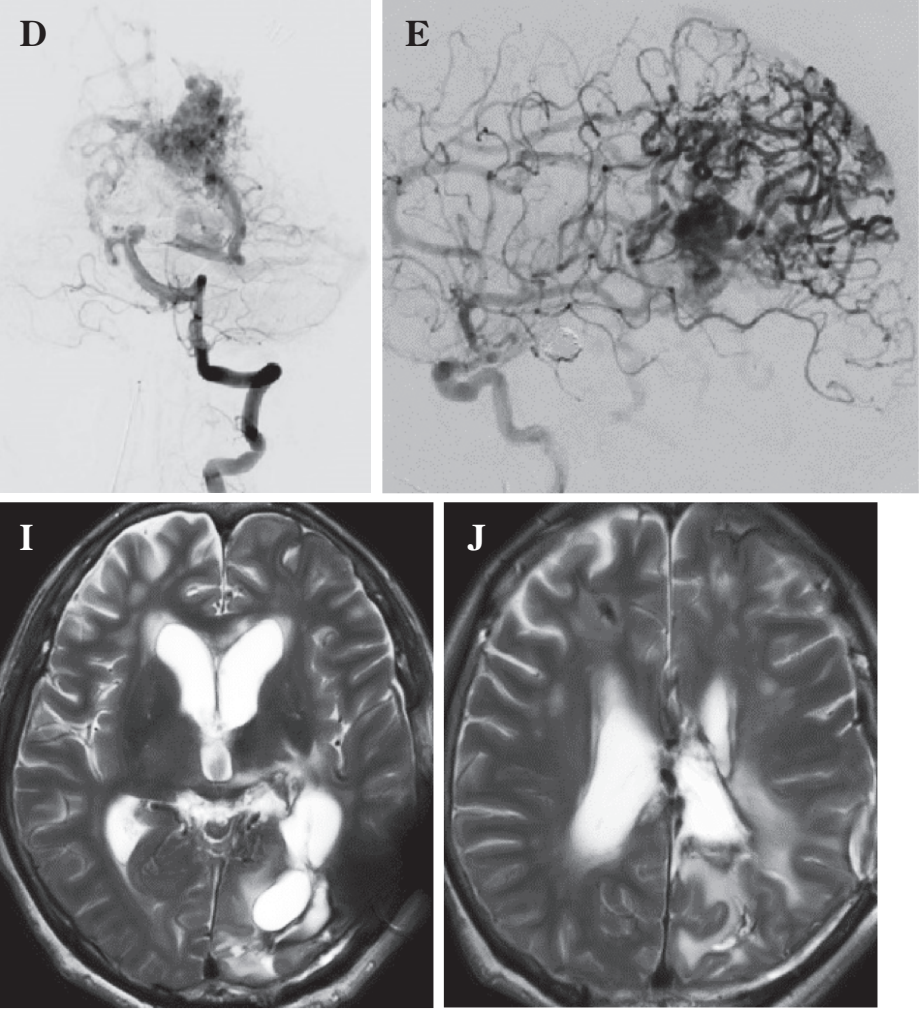

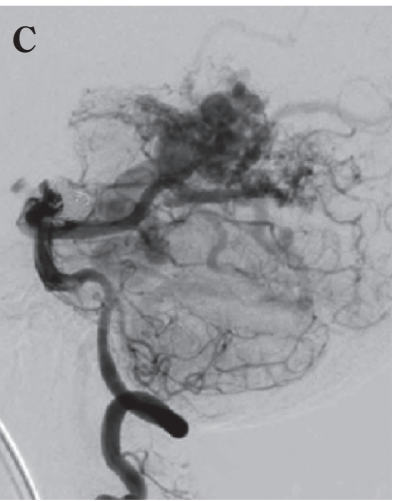

F
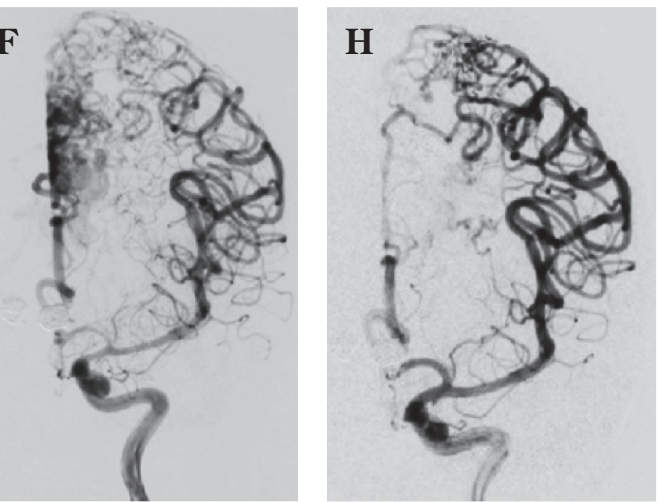

Fig. 3 Representative cases of staged TAE and resection in patients with high-flow AVM presenting with repeated hemorrhage despite previous SRS and TAE

The patients showed mild right-sided hemiparesis and right-sided hemianopia before treatment.

A, B : Preoperative contrast-enhanced CT images showing the localization of AVM.

C- F : Preoperative angiograms showing high-flow huge posterior callosal-left parietal AVM fed by posterior/anterior/middle cerebral arteries draining into the vein of Galen.

G, H : Angiograms after staged TAE of feeders from posterior choroidal and anterior cerebral arteries.

I , J : Postoperative T2-weighted MR images showing disappearance of the AVM. After surgery, the patient recovered without neurological deterioration.

り，外科治療の安定性およびその成績は大型や eloquent areaのものでも飛躍的に向上している(1)-3)7716)18)19)。一方 で, multimodal treatmentの定着により4)722223)26), 直達 術が選択される機会は年々減少し, 特に 2014 年に ARUBA study ${ }^{20)}$ が発表されてからは，その傾向がより顕 著である ${ }^{24)}$. 結果, 最近では各施設間でAVM に対する 治療方針に大きな隔たりが生じ, 治療の均露化と個別最
適化をどのように両立していくかが新たな問題になりつ つある。

従来から, 多くの先進施設の low-grade AVM の手術成 績 ${ }^{12)}$ は自然歴を大きく凌ぐものであったが, high-grade AVM に関しては高い morbidity が報告され, その適応が 議論の的であった。しかし最近は前述の 3D-angiography, CT, MRI, ultrasound, indocyanine green-videoan- 

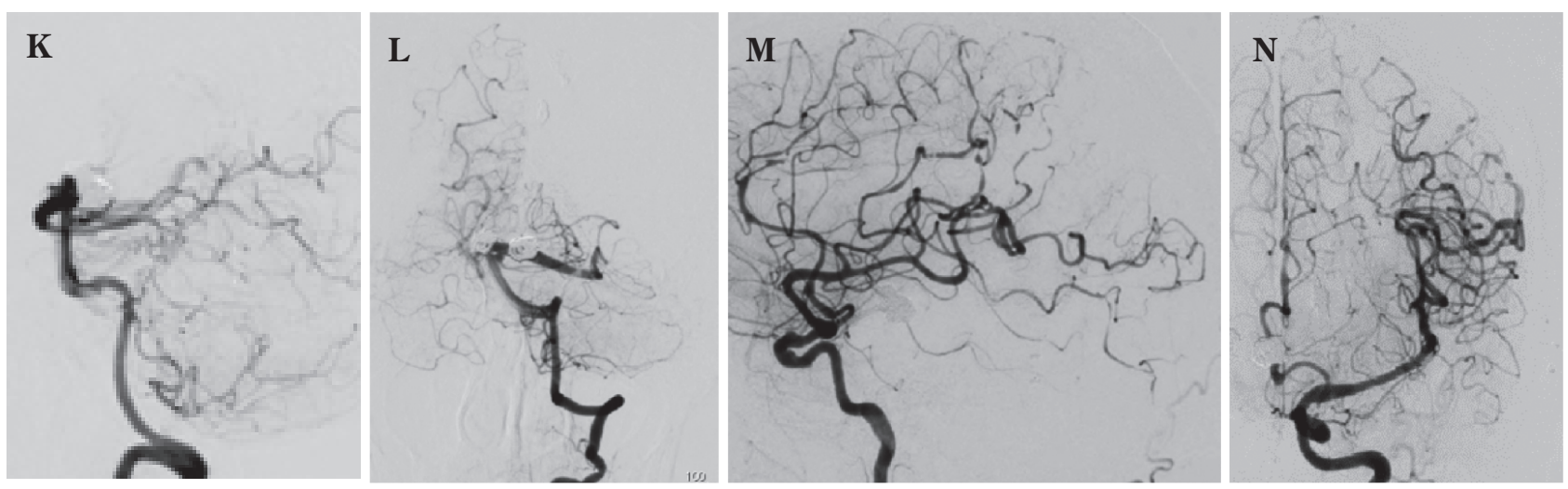

Fig. 3 (cont'd)

$\mathbf{K}-\mathbf{N}$ : Postoperative angiograms showing total elimination of the arteriovenous (AV) shunt.

Nidus : $8 \times 5 \times 4 \mathrm{~cm}$

Feeder : Lt PCA chroidal a, ACA, MCA, MMA, OA

Drainer: SSS, Galen, basal vein, petrosal vein
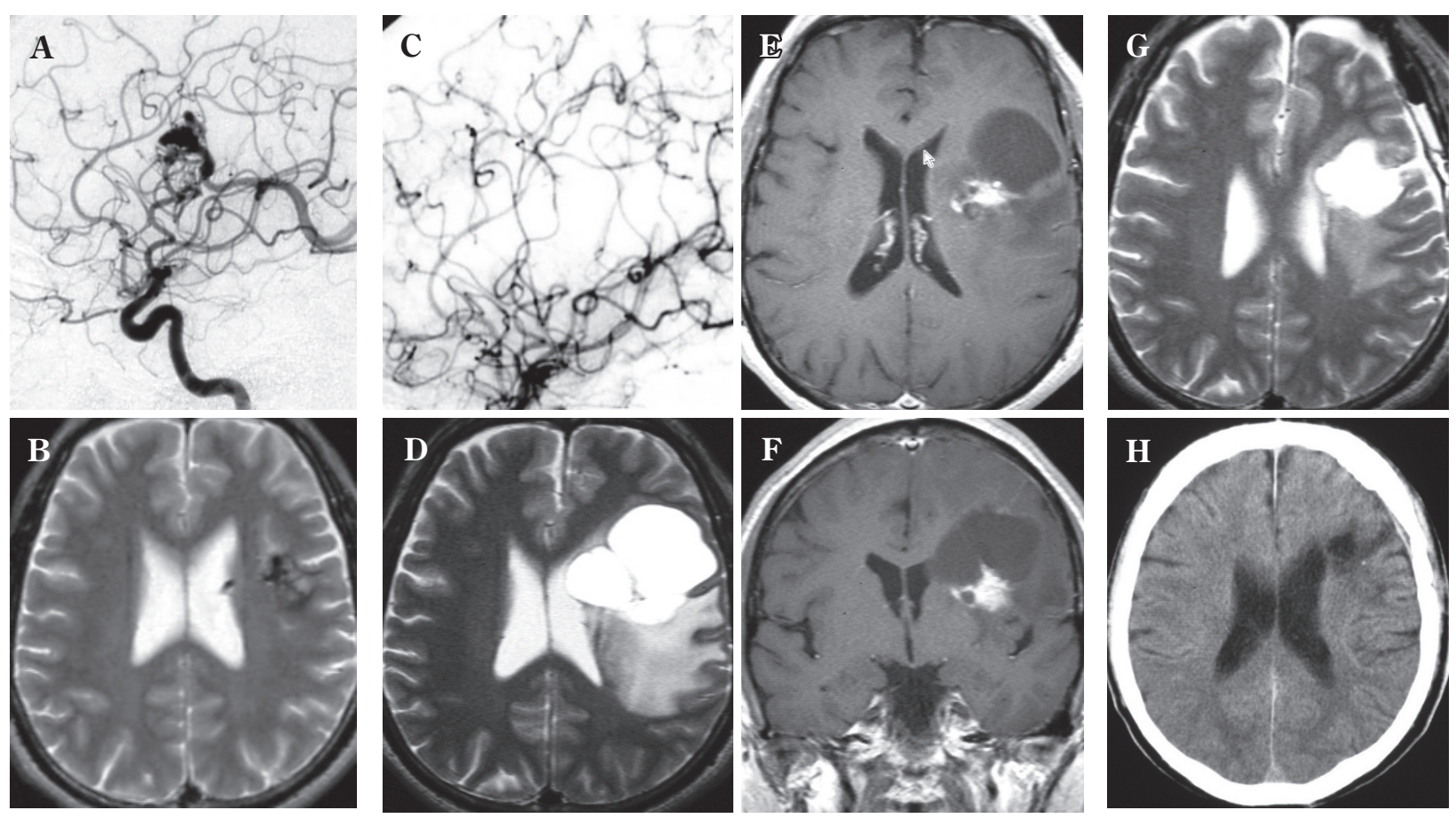

Fig. 4 A representative case of symptomatic degenerate AVM after SRS

The patient experienced progressive aphasia 5 years after SRS.

A : Initial angiogram showing small left frontal AVM.

B : Initial T2-weighted MR image showing localization of the nidus.

C : Angiogram obtained 5 years after SRS, showing total obliteration of AVM.

D : T2-weighted MR image obtained 5 years after SRS, demonstrating large cyst and brain edema around the obliterated AVM.

E, F : Contrast-enhanced T1-weighted MR images showing contrast-enhanced degenerate nidus and radiation necrosis on the wall of the cyst.

G : T2-weighted MR image obtained 1 month after surgery, showing shrinking of the cyst.

$\mathbf{H}:$ CT image obtained 3 months after the surgery, showing no recurrence of the cyst. 
giography などの術中画像支援に加え, motor evoked potential (MEP)/sensory evoked potential (SEP) /auditory brainstem response（ABR）などの電気生理学的 monitoring の普及により, high-grade 症例の成績は向上してお

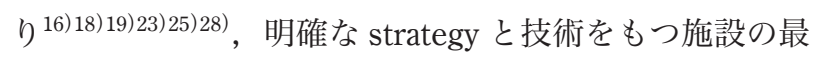
近の手術成績は ARUBAの内科的治療群を凌いでお $\eta^{5) 25)}$, 今後最近の手術成績が蓄積されていけば, 将来 主たる治療 modalityが外科治療に再シフトする可能性が ある ${ }^{6)}$.

また, 治療の適応に際しても, 従来は出血例, 非出血 例で区別されるのみであったが, 後者にはまったくの無 症状のものから, 1 回の痤攣発作や頭痛の screening で発 見されたもの, AVMによる症候性難治性てんかんや, 進 行性の神経学的悪化を呈しているものなど, 治療の必要 度は症例ごとに大きく異なり, 個々の症例に応じて慎重 かつ適確に外科適応が考慮されなければならない. 疾患 の希少性に加え, 多彩な神経学的症候, 治療手段の多様 性から, 今後も外科治療の適応や有効性を科学的に実証 する randomized study の実現には大きな困難が予想され る。しかし, 従来の AVM の topography のみによる手術 grading に, (1)出血歷の有無と, 非未出血例の症候の severity, (2)既存の神経学的欠落症状の有無, (3)出血例で は周囲脳の損傷の程度 ${ }^{17)}$ (血腫の大きさ)などの患者側の より詳細な因子とともに, 最近の集学的手術支援下の AVM 直達術の成績が反映された新たな術前評価システ ムの確立が急務である。

AVM に対して複数の治療が選択できる現在, 直達術 に許容される morbidityの幅はきわめて狭く, 今後は radiosurgery をはじめとして, 各種先行治療を受けた変 性 AVM に対する salvage treatment としての役割も一層 高まっていくであろう。一方, 1 人の脳血管外科医が経 験できる症例数は減少していくことが予想され, 今後は “super-subspecialized surgery”として, 限定した術者の みが施行すべきという意見も聞かれる。次代を担うAVM surgeonをいかに育成し，どのように配置していくかが， 喫緊の課題である.

\section{まとめ}

Multimodal treatment 時代に, 外科手術は減少したが, 各種手術支援により治療成績は向上し, 先行治療を受け た症例の割合が増加した. 今後も multimodal treatment の核として，直達術が考慮されていくべきであるが，そ のためには新たな手術適応基準の確立と, 計画的な術者 育成が必要不可欠である。

\section{Disclosure}

本論文の要旨は, 第 40 回日本脳神経外科コングレス・プレ ナリーセッション「出血性脳血管障害」(2020 年 8 月 10 日) において発表した。筆頭著者および共同著者は日本脳神経外 科学会会員であり, 同学会への COI 自己申告を完了してい る. 本論文に関して開示すべき COI はない.

\section{文 献}

1) Bendok BR, El Tecle NE, Ahmadieh TY, Koht A, Gallagher TA, Carroll TJ, Markl M, Sabbagha R, Sabbagha A, Cella D, Nowinski C, Dewald JP, Meade TJ, Samson D, Batjer HH : Advances and innovations in brain arteriovenous malformation surgery. Neurosurgery 74 (Suppl 1) : S60-S73, 2014.

2) Bervini D, Morgan MK, Ritson EA, Heller G : Surgery for unruptured arteriovenous malformations of the brain is better than conservative management for selected cases : a prospective cohort study. J Neurosurg 121:878-890, 2014.

3) Burkhardt JK, Lasker GF, Winkler EA, Kim H, Lawton MT : Microsurgical resection of brain arteriovenous malformations in the elderly: outcomes analysis and risk stratification.J Neurosurg 129:1107-1113,2019

4) Crowley RW, Ducruet AF, Kalani MY, Kim LJ, Albuquerque FC, McDougall CG : Neurological morbidity and mortality associated with the endovascular treatment of cerebral arteriovenous malformations before and during the Onyx era. $J$ Neurosurg 122: 1492-1497, 2015.

5) Hernesniemi J, Romani R, Lehecka M, Isarakul P, Dashti R, Celik O, Navratil O, Niemelä M, Laakso A : Present state of microneurosurgery of cerebral arteriovenous malformations. Acta Neurochir Suppl 107: 71-76, 2010.

6) Kato Y, Dong VH, Chaddad F, Takizawa, K Izumo T, Fukuda H, Hara T, Kikuta K, Nakai Y, Endo T, Kurita H, Xu B, Beneš V, Raftopoulos C, Pavesi G, Hodaie M, Sharma RK, Agarwal H, Mohan K, Liew BS : Expert consensus on the management of brain arteriovenous malformations. Asian J Neurosurg 14:1074-1081, 2019.

7) Kotowski M, Sarrafzadeh A, Schatlo B, Boex C, Narata AP, Pereira VM, Bijlenga P, Schaller K : Intraoperative angiography reloaded : a new hybrid operating theater for combined endovascular and surgical treatment of cerebral arteriovenous malformations : a pilot study on 25 patients. Acta Neurochir (Wien) $155:$ 2071-2078, 2013.

8）栗田浩樹, 石原正一郎, 大井川秀聡, 小倉丈司, 竹田理々 子, 伏原豪司, 吉川信一朗, 大塚宗廣, 岡田大輔, 鈴木 海馬, 柳川太郎, 佐藤大樹: AVM 直達術の術中画像支 援一hybrid 手術室 (BRAIN OR) の有用性. Mt. Fuji Workshop on CVD 30:122-127, 2012.

9）栗田浩樹, 大井川秀聡, 竹田理々子, 中島弘之, 小倉丈 司, 池田俊貴, 吉川信一郎, 大塚宗廣, 鈴木海馬, 佐藤 大樹, 柳川太郎, 柴田碧人, 池田峻介: 脳動静脈奇形と 硬膜動静脈瘻の直達術一なにが同じでなにが異なるの か? 脳外誌 22:904-910, 2013.

10）栗田浩樹, 竹田理々子, 池田俊貴, 吉川雄一郎, 伏原豪 司, 大井川秀聡, 小倉丈司, 石原正一郎：脳動脈瘤・脳 動静脈奇形に対する hybrid 手術の現状と展望一直達術の 立場より。脳外誌 24:173-179, 2015.

11）栗田浩樹, 神山信也：脳血管外科の今を知る(5) 血管内 塞栓術を生かした脳動静脈奇形（AVM）外科治療.脳外 速報 27:369-373， 2017 . 
12）栗田浩樹, 竹田理々子, 吉川雄一郎, 池田俊貴, 寺西亮 雄, 池上方基, 武裕士郎, 鈴木隼, 大井川秀聡, 神山信 也：Multimodality 時代の脳動脈瘤直達術。脳外誌 28 ： 127-133, 2019.

13）栗田浩樹：第 3 章。脳動静脈奇形の治療- II 。脳 AVM（S \& M grade III-IV) の外科治療. 中瀬裕之編：プライム脳 神経外科 第 3 巻: 脳・脊髄動静脈奇形と頭蓋内・脊䯣 硬膜動静脈瘻。東京，三輪書店，2019，pp.73-79.

14）栗田浩樹：SM Grade 3 の脳動静脈奇形の治療（開頭手 術)。黒田 敏編：NS NOW シリーズ 18 Neurosurgical Controversies 脳神経外科の最新ディベート. 東京, メ ジカルビュー, 2019, pp.128-134.

15）栗田浩樹：VI. 脳血管障害. (4)脳動静脈奇形摘出術 - 硬 膜動静脈瘻手術。吉村紳一監, 吉本幸司編：脳神経外科 速報 2019 年増刊号 専門医なら知っておきたい疾 患・術式別脳神経外科手術合併症の回避・対処法 Q \& A 156. 大阪, メディカ出版, 2019, pp.140-146.

16) Lawton MT; UCSF Brain Arteriovenous Malformation Study Project: Spetzler-Martin grade III arteriovenous malformationos : surgical results and a modification of grading scale. Neurosurgery $\quad \mathbf{5 2}: 740-748,2003$.

17) Lawton MT, Du R, Tran MN, Achrol AS, McCulloch CE, Johnston SC, Quinnine NJ, Young WL : Effect of presenting hemorrhage on outcome after microsurgical resection of brain arteriovenous malformations. Neurosurgery 56 : 485-493, 2005.

18) Lin F, Jiao Y, Wu J, Zhao B, Tong X, Jin Z, Cao Y, Wang S : Effect of functional MRI-guided navigation on surgical outcomes: a prospective controlled trial in patients with arteriovenous malformations. J Neurosurg 126:1863-1872, 2017.

19) Mascitelli JR, Yoon S, Cole TS, Kim H, Lawton MT : Does eloquence subtype influence outcome following arteriovenous malformation surgery? J Neurosurg 131:876-883, 2018.

20) Mohr JP, Parides MK, Stapf C, Moquete E, Moy CS, Overbey JR, Al-Shahi Salman R, Vicaut E, Young WL, Houdart E, Cordonnier C, Stefani MA, Hartmann A, von Kummer R, Biondi A, Berkefeld J, Klijn CJ, Harkness K, Libman R, Barreau X, Moskowitz AJ ; international ARUBA investigators: Medical management with or without interventional therapy for unruptured brain arteriovenous malformations (ARUBA) : a multicentre, non-blinded, randomised trial. Lancet $383: 614-621,2014$.

21) Ogilvy CS, Stieg PE, Awad I, Brown RD Jr, Kondziolka D, Rosenwasser R, Young WL, Hademenos G ; Special Writing Group of the Stroke Council, American Stroke Association: AHA Scientific Statement: Recommendations for the management of intracranial arteriovenous malformations : a statement for healthcare professionals from a special writing group of the Stroke Council, American Stroke Association. Stroke 32 : 1458-1471, 2001.

22) Pandey P, Marks MP, Harraher CD, Westbroek EM, Chang SD, Do HM, Levy RP, Dodd RL, Steinberg GK : Multimodality management of Spetzler-Martin Grade III arteriovenous malformations. J Neurosurg $\quad 116: 1279-1288,2012$.

23) Potts MB, Jahangiri A, Jen M, Sneed PK, McDermott MW, Gupta N, Hetts SW, Young WL, Lawton MT ; UCSF Brain AVM Study Project: Deep arteriovenous malformations in the basal ganglia, thalamus, and insula: multimodality management, patient selection, and results. World Neurosurg 82: 386-394, 2014.

24) Reynolds AS, Chen ML, Merkler AE, Chatterjee A, Díaz I, Navi BB, Kamel H : Effect of ARUBA on interventional treatment rates for unruptured arteriovenous malformations. Cerebrovasc Dis $47: 299-302,2019$.

25) Rutledge WC, Abla AA, Nelson J, Halbach VV, Kim H, Lawton MT: Treatment and outcomes of ARUBA-eligible patients with unruptured brain arteriovenous malformations at a single institution. Neurosurg Focus 37: E8, 2014.

26) Sasaki T, Kurita H, Saito I, Kawamoto S, Nemoto S, Terahara A, Kirino T, Takakura $\mathrm{K}$ : Arteriovenous malformation of the basal ganglia and thalamus : treatment and results in 101 cases.J Neurosurg 88: 285-292, 1998.

27) Spetzler RF, Martin MA : A proposed grading system for arteriovenous malformations. J Neurosurg $\mathbf{6 5}: 476-483$, 1986.

28) Wang M, Jiao Y, Cao Y, Wang S, Zhao J : Surgical management of complex brain arteriovenous malformations with hybrid operating technique : study protocol of a prospective registry and a pragmatic clinical trial. BMC Neurol $19: 75$, 2019.

\section{旨}

脳動静脈奇形の病態と治療：Multimodal treatment 時代の直達術の現状と将来展望

栗田 浩樹 吉川雄一郎 池田 俊貴 竹田理々子

鈴木 海馬鈴木 隼 上出 智也

Multimodal treatment の普及や ARUBA study の結果から, 脳動脈奇形（AVM）に対する直達術は最 近減少したが, 一方治療成績は各種手術支援により飛躍的に向上している. 本稿では当科における AVM 直達術の現状を報告し, 今後 AVM に対する治療の標準化と個別最適化に際して, 直達術が果た すべき役割と確立すべき新たな適応基準について考察した. 